\title{
Luminescence properties and compositions of contaminating inorganic minerals separated from gamma-irradiated fresh and white ginsengs from different areas
}

\author{
Jae-Jun Ahn', Kashif Akram ${ }^{1,2}$, Mi-Seon Jeong ${ }^{1}$, Ji-Young Kwak ${ }^{1}$, Eun-Joo Park ${ }^{1}$, and Joong-Ho Kwon ${ }^{1, *}$ \\ ${ }^{1}$ School of Food Science \& Biotechnology, Kyungpook National University, Daegu 702-701, Korea \\ ${ }^{2}$ Institute of Food Science and Nutrition, University of Sargodha, Sargodha 40100, Pakistan
}

Gamma-irradiation (0-7 kGy) of ginseng is permitted in Korea for the purpose of microbial decontamination; with strict labeling, traceability and monitoring requirements. An identification study was conducted to determine the photostimulated-luminescence (PSL) and thermoluminescence (TL) properties of gamma-irradiated fresh and white ginsengs cultivated in different areas. Dosedependent PSL-based screening was possible for white ginseng samples; however, inappropriate results from non-irradiated fresh ginseng samples were obtained, showing intermediate $(700$ to 5,000$)$ or positive $\left(T_{2}>5,000\right.$, irradiated) PSL counts due to the abundance of minerals on the surfaces of the samples. TL analysis of separated minerals from all non-irradiated samples gave TL glow curves of low intensity with a maximum peak after $300^{\circ} \mathrm{C}$. However, well-defined irradiation-specific (high intensity with a maximum peak at about $200^{\circ} \mathrm{C}$ ) glow curves were observed for all the irradiated samples, regardless of their type and origins. TL ratios (first glow curve /second glow curve) were also determined to confirm the irradiated $(>0.1)$ and non-irradiated $(<0.1)$ results. SEM-EDX (scanning electron microscope-energy dispersive X-ray) and XRD (X-ray diffraction) spectroscopic analyses showed that feldspar and quartz minerals were the main source for the typical radiation-specific luminescence properties.

Keywords: Ginseng, Gamma-irradiation, Photostimulated-luminescence, Thermoluminescence, SEM-EDX analysis

\section{INTRODUCTION}

Medicinal plants, enriched with different functional compounds, could enhance human health with their potent therapeutic benefits. Among them, Korean ginseng (Panax ginseng Meyer) is widely used in Asia, especially as an ingredient in traditional Chinese medicine and has also gained world-wide popularity, mainly in the United States and Europe, due to its immune system enhancing and antioxidant activities [1].

Ginseng is harvested as fresh roots, which, like other agricultural commodities, could be contaminated by spoilage or pathogenic microorganisms during harvest-

(c) This is an Open Access article distributed under the terms of the Creative Commons Attribution Non-Commercial License (http://creativecommons.org/licenses/by-nc/3.0/) which permits unrestricted non-commercial use, distribution, and reproduction in any medium, provided the original work is properly cited. ing, processing, transportation, storage, or post-harvest treatment. This is a serious threat especially for the medicinal use of ginseng in which the conventional techniques to address microbial contamination, such as fumigation with gaseous ethylene oxide or methyl bromide, are prohibited or restricted for different health safety concerns [1,2]. Food irradiation could be used as an effective approach to cope with microbial safety issues, where different scientists have reported the improved hygienic quality $[3,4]$ and shelf life $[5,6]$ of ginseng and its products without any major compromise to key quality attri-

Edited by Sang-Kook Lee, Seoul National University, Korea

Received 04 Oct. 2012, Revised 13 Jul. 2013, Accepted 23 Jul. 2013

*Corresponding author

E-mail: jhkwon@knu.ac.kr

Tel: +82-53-950-5775, Fax: +82-53-950-5775 
butes. Korean ginseng products have emerged on global markets; especially, Hong Kong, Japan, North America, and different European countries are major buyers. Better access to international markets with improved quality is possible using irradiation technology [7].

Different national and international regulations regarding proper monitoring and traceability of irradiation processes and products are being enforced which require proper labeling and reliable identification about irradiated products [8]. Among others, radiation-specific luminescence properties could be used effectively to characterize the irradiation status of samples. Photostimulatedluminescence (PSL) analysis is a quick approach without any complicated sample pretreatment [9]. However, the results could vary greatly depending upon the quantity and quality of the contaminating minerals on the surfaces of the samples [10]. The European standard EN 13751 [9] has recommended PSL analysis as a screening approach, requiring reliable confirmation through a reference method. In order to confirm the PSL results, thermoluminescence (TL) analysis could be used for any food material from which enough (about $0.2 \mathrm{mg}$ ) of a silicate enriched mineral fraction can be separated. The radiation-specific properties of the TL glow curve could provide conclusive information on the irradiation history of samples [11,12]. The quality and quantity of silicate minerals (quartz, feldspar, etc.) have a prime role in the key TL properties. Because contaminating (from the environment) silicate minerals are used, the origin of the product describing the composition of the minerals available for the analysis is very important [12].

In this study, the PSL technique was used as a screening approach for the irradiated ginseng samples while TL analysis was conducted for the subsequent confirmation of irradiation status of the samples. The effect the cultivation areas had on the contaminating minerals that were separated from the samples was also investigated with $\mathrm{X}$ ray diffraction (XRD) and scanning electron microscopeenergy dispersive X-ray (SEM/EDX) spectroscopy for a better understanding of the radiation-specific luminescence properties.

\section{MATERIALS AND METHODS}

\section{Samples and irradiation}

Fresh and white (dried) ginseng roots, cultivated in the Punggi, Geumsan, Gimpo, and Gangwon areas of Korea and harvested at the after of 6 years of growth, were obtained from a local market in Korea. The samples were irradiated $(0,1,4$, and $7 \mathrm{kGy})$ using a Co-60 gamma-ray source (dose rate $1.5 \mathrm{kGy} / \mathrm{h}$; AECL, IR-79; MDS Nordion International, Ottawa, ON, Canada) at the Korean Atomic Energy Research Institute, in Jeongeup, Korea. The applied doses were calibrated using alanine dosimeters with a $5 \mathrm{~mm}$ diameter (Bruker Instruments, Rheinstetten, Germany), and, the free-radical signals were determined using a Bruker EMS 104 EPR analyzer (Bruker Instruments).

\section{Photostimulated-luminescence measurements}

The PSL measurements were done with a pulsed photo-stimulated luminescnece system (serial 0021; Scottish Universities Research and Reactor Center, Glasgow, UK) The samples were cut into small pieces to fill in $50 \mathrm{~mm}$ diameter disposable petri dishes (Bibby sterilin type 122), and the photon counts (PCs)/ $60 \mathrm{~s}$ were measured in the sample chamber as described in the European standard EN 13751 [9]. The samples with PCs less than 700 were considered as negative (non-irradiated) and more than 5,000 were considered as positive (irradiated), whereas the values between these two limits were classified as intermediate requiring further investigation to confirm the results. All samples were measured in triplicate $(n=3)$ under the same laboratory and instrumental conditions.

\section{Thermoluminescence measurements}

The PSL screening results were confirmed by the TL analysis, which was done as described in the European standard EN 1788 [12]. A sample was washed with distilled water on a nylon sieve $(150 \mu \mathrm{m})$ and contaminating minerals were obtained thorough the density separation technique. The separated minerals (about $0.2 \mathrm{mg}$ ) were loaded onto TL discs and the analysis was performed with a thermoluminescence dosimeter system reader (Harshaw 4500; Thermo Fisher Scientific, Waltham, MA, USA) under a pure $\mathrm{N}_{2}$ gas (99.999\%) flush. The first TL glow curve $\left(\mathrm{TL}_{1}\right)$ was obtained at a temperature increase rate of $5^{\circ} \mathrm{C} / \mathrm{s}$ from 50 to $400^{\circ} \mathrm{C}$. To normalize the $\mathrm{TL}_{1}$ results, the tested minerals were re-irradiated ( $1 \mathrm{kGy}$ ), and the second TL glow curve $\left(\mathrm{TL}_{2}\right)$ was measured. Finally, the $\mathrm{TL}$ ratio (integrated area of $\mathrm{TL}_{1} / \mathrm{TL}_{2}$ between 150 and $250^{\circ} \mathrm{C}$ ) was calculated. The TL glow curve shape, intensity, and TL ratio were used to interpret the identification results [12].

\section{X-ray diffraction measurements}

The inorganic mineral dust $(0.5 \mathrm{~g})$ separated from the ginseng sample by washing was characterized using a multipurpose X-ray diffractometer (X'Pert Pro; PANalytical, Almelo, The Netherlands) at the Korea Basic Sci- 
ence Institute, Daegu. Silicon powder (corundum) was used as a standard reference material to calibrate the Xray diffractometer. The analysis was performed under the following measurement conditions: $\mathrm{X}^{\prime}$ Celerator (ultrafast) detector; 0 to 60 degrees of scan angle; $11.9 \mathrm{deg} / \mathrm{s}$ of scan rate, Gonio of scan axis; continuous scan mode; and radiations of $\mathrm{Cu} \mathrm{K \alpha}$ with a wavelength of 1.540598 $\AA$. The XRD spectral measurements were done between 0 and $60^{\circ} \theta$ at a $2^{\circ} \theta$ scan, where the each peak was identified using with reference data.

\section{Scanning electron microscopy-energy dispersive $\mathrm{X}$-ray measurements}

SEM/EDX analysis was done to determine the polymineral composition of the isolated minerals from the ginseng samples. A field emission scanning electron microscope (model S4300; Hitachi, Tokyo, Japan) equipped with an EDX spectrometer was used at accelerating voltage of $15 \mathrm{kV}$.

\section{Statistical analysis}

All measurements were done in triplicate $(n=3)$ and the mean \pm standard deviation values are presented. Origin ver. 6.0 software (Microcal Software, Northampton, MA, USA) was used for the data analysis and presentation.

\section{RESULTS AND DISCUSSION}

\section{Photostimulated-luminescence characteristics}

PSL analysis is a time-efficient technique which results in easy screening of irradiated samples according to their irradiation history [9]. Table 1 presents the PSL results for the control and irradiated fresh and white ginseng samples, cultivated and harvested in different areas of Korea. All non-irradiated white ginseng samples had negative PSL counts ( $<700$ PCs) with negligible differences. However, non-irradiated fresh ginseng samples were intermediate (700 to 5,000 PCs), except for one that was positive $(>5,000 \mathrm{PCs})$. The excessive amount of contaminating minerals could be the cause of these false intermediate and positive results [9]. Different scientists studying the irradiation status of onions $[13,14]$ and tea [15] also reported similar results. In this case, an in-house re-irradiation and calibration of the PSL results provided conclusive information. The large differences between the PSL counts of the non-irradiated and $1 \mathrm{kGy}$-irradiated samples represented the possibility of the absence of irradiation treatment, even if the results from the nonirradiated samples were false positives [9].

All irradiated samples were positive, regardless of the type and origins of the samples; however, there were considerable differences among the samples for the same type and irradiation dose. This variability in the PSL results might be due to variations in the quantity and quality of the contaminating minerals on the surfaces of the samples [9]. Other scientists have also reported great variability in PSL results, even in the case of different replications from the same sample $[10,16]$ and suggested that PSL technique could only be used to screen large sample lots; however, the results should be confirmed with a reliable identification technique [9].

\section{Thermoluminescence characteristics}

The TL analysis was done as a confirmatory or reference technique to identify the irradiation status of fresh and white ginsengs. Different studies have established that TL analysis results are not dependent on the kind of food, but on the quantity and quality of the separated silicate minerals [12]. All non-irradiated ginseng samples had a low-intensity TL glow curve with a maximum peak

Table 1. Photostimulated-luminescence results from non-irradiated and irradiated fresh and white ginsengs cultivated in different areas

\begin{tabular}{|c|c|c|c|c|c|}
\hline \multirow{2}{*}{ Sample } & \multirow{2}{*}{$\begin{array}{c}\text { Producing } \\
\text { area }\end{array}$} & \multicolumn{4}{|c|}{ Irradiation dose (kGy) } \\
\hline & & 0 & 1 & 4 & 7 \\
\hline \multirow[t]{4}{*}{ Fresh ginseng } & Punggi & $4,029 \pm 1,398(\mathrm{M})^{1)}$ & $91,005 \pm 3,686(+)$ & $1,003,948 \pm 23,434(+)$ & $557,332 \pm 34,384(+)$ \\
\hline & Geumsan & $1,694 \pm 1,227(\mathrm{M})$ & $304,958 \pm 117,349(+)$ & $594,029 \pm 98,588(+)$ & $738,401 \pm 23,783(+)$ \\
\hline & Gimpo & $7,095 \pm 3,429(+)$ & $398,402 \pm 55,661(+)$ & $1,212,465 \pm 70,932(+)$ & $3,304,958 \pm 10,838(+)$ \\
\hline & Gangwon & $3,948 \pm 1,221(\mathrm{M})$ & $248,396 \pm 67,224(+)$ & $475,061 \pm 54,791(+)$ & $1,004,856 \pm 47,695(+)$ \\
\hline \multirow[t]{4}{*}{ White ginseng } & Punggi & $318 \pm 98(-)$ & $22,756 \pm 2,586(+)$ & $44,129 \pm 434(+)$ & $75,048 \pm 384(+)$ \\
\hline & Geumsan & $307 \pm 17(-)$ & $50,980 \pm 1,529(+)$ & $77,392 \pm 988(+)$ & $94,037 \pm 283(+)$ \\
\hline & Gimpo & $335 \pm 9(-)$ & $33,486 \pm 3,561(+)$ & $100,294 \pm 7,092(+)$ & $77,496 \pm 10,838(+)$ \\
\hline & Gangwon & $314 \pm 21(-)$ & $9,047 \pm 3,724(+)$ & $13,744 \pm 5,479(+)$ & $68,039 \pm 7,496(+)$ \\
\hline
\end{tabular}

Vaules are presented as mean \pm standard deviation $(n=3)$

${ }^{1)}$ Threshold value: $T_{1}=700, T_{2}=5000,(-)<T_{1}, T_{1}<(M)<T_{2},(+)>T_{2}$ 

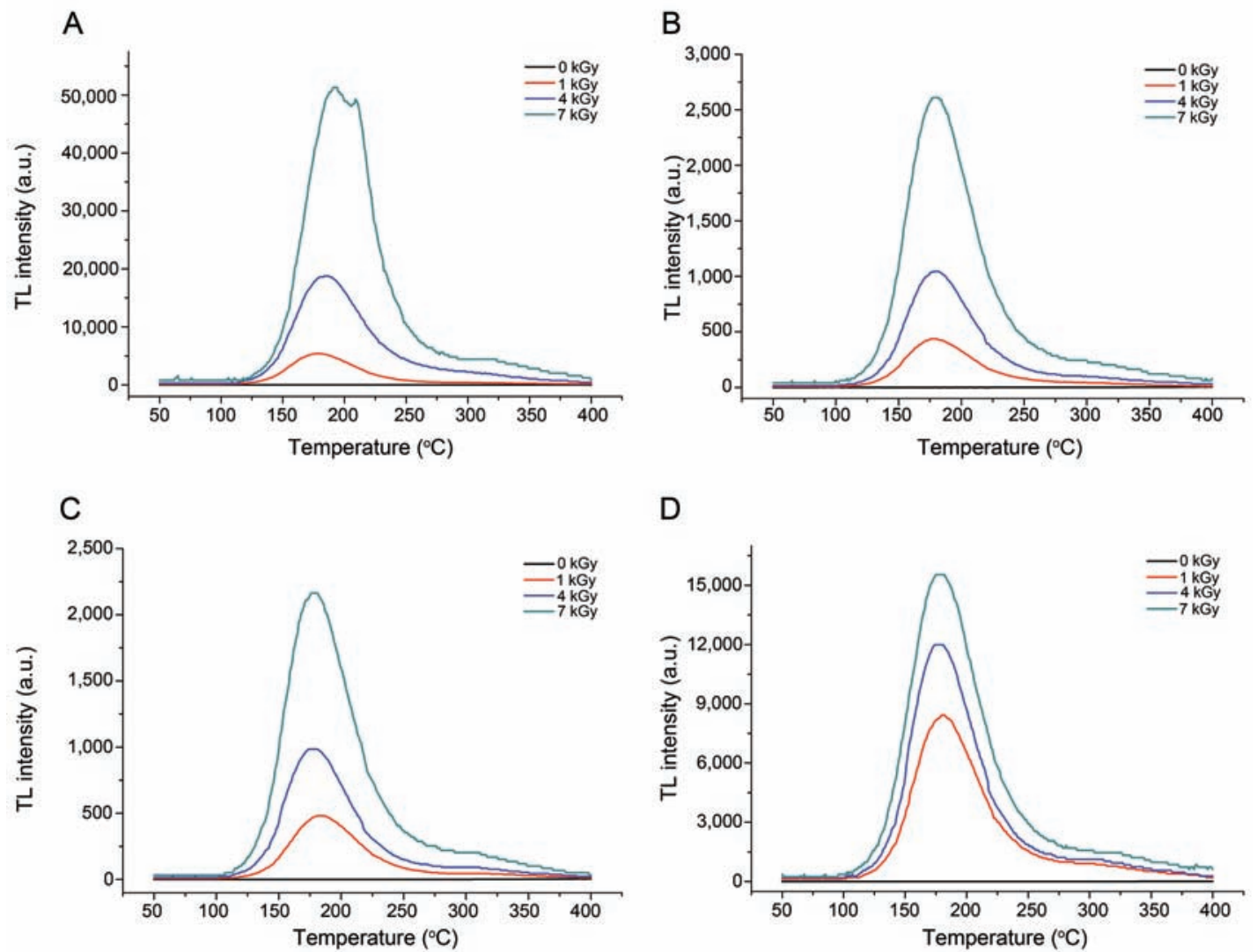

Fig. 1. Thermoluminescence (TL) glow curves of contaminating inorganic minerals separated from gamma-irradiated fresh ginsengs cultivated in different areas. (A) Punggi region, (B) Geumsan region, (C) Gangwon region, and (D) Gimpo region.

Table 2. Thermoluminescence $(T L)$ ratio $\left(T_{1} / T L_{2}\right)$ of contaminating inorganic minerals separated from non-irradiated and irradiated fresh and white ginsengs cultivated in different areas

\begin{tabular}{llcccc}
\hline \multirow{2}{*}{ Sample } & Cultivated & \multicolumn{4}{c}{ Irradiation dose $(\mathrm{kGy})$} \\
\cline { 3 - 5 } area & \multicolumn{1}{c}{0} & 1 & 4 & 7 \\
\hline Fresh ginseng & Punggi & $0.001 \pm 0.000$ & $0.241 \pm 0.048$ & $0.311 \pm 0.074$ & $0.617 \pm 0.152$ \\
& Geumsan & $0.026 \pm 0.583$ & $0.814 \pm 0.354$ & $1.469 \pm 0.873$ & $4.354 \pm 1.008$ \\
& Gangwon & $0.035 \pm 0.006$ & $0.462 \pm 0.039$ & $2.545 \pm 1.595$ & $1.565 \pm 0.336$ \\
\multirow{2}{*}{ White ginseng } & Gimpo & $0.011 \pm 0.005$ & $0.288 \pm 0.004$ & $0.422 \pm 0.039$ & $0.608 \pm 0.125$ \\
& Punggi & $0.005 \pm 0.001$ & $0.256 \pm 0.056$ & $0.336 \pm 0.162$ & $0.415 \pm 0.137$ \\
& Geumsan & $0.004 \pm 0.007$ & $0.325 \pm 0.158$ & $1.102 \pm 0.374$ & $2.287 \pm 0.386$ \\
& Gangwon & $0.013 \pm 0.007$ & $0.125 \pm 0.057$ & $0.333 \pm 0.096$ & $0.549 \pm 0.155$ \\
& Gimpo & $0.058 \pm 0.007$ & $0.389 \pm 0.107$ & $0.251 \pm 0.039$ & $0.472 \pm 0.134$
\end{tabular}

Values are presented as mean \pm standard deviation $(n=3)$.

after $300^{\circ} \mathrm{C}$ (Figs. 1 and 2). The TL peak after $300^{\circ} \mathrm{C}$ was due to a natural geological signal; however there was no peak in the radiation-specific temperature range $\left(150^{\circ} \mathrm{C}\right.$ to $250^{\circ} \mathrm{C}$ ) of the $\mathrm{TL}$ glow curve, showing the absence of any irradiation history [12]. All irradiated ginseng samples revealed typical radiation-specific TL glow curves with maximum peaks of high intensities at about $200^{\circ} \mathrm{C}$. A clear discrimination of non-irradiated and irradiated samples was possible. The dose-dependency of the TL glow curve intensity was most prominent in samples from the Punggi region, whereas the same was comparatively less obvious in the sample from the Gimpo region. The composition of the minerals and their relative sensitivity to irradiation treatment might be the cause for this variation [13].

In the TL analysis, the same minerals (already mea- 
Ahn et al. Luminescence characteristics of irradiated ginsengs
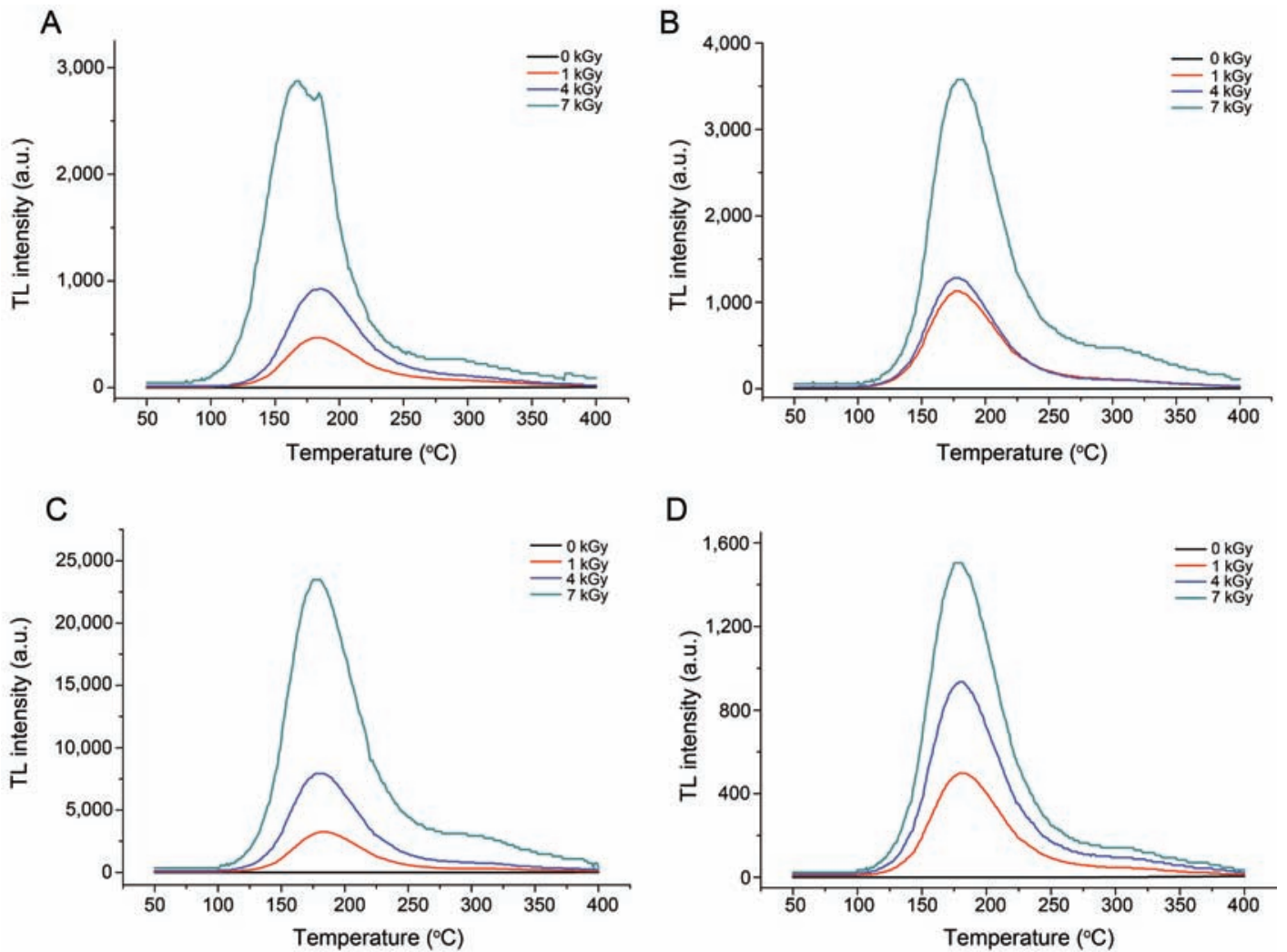

Fig. 2. Thermoluminescence (TL) glow curves of contaminating inorganic minerals separated from gamma-irradiated white ginsengs cultivated in different areas. (A) Punggi region, (B) Geumsan region, (C) Gangwon region, and (D) Gimpo region.

A

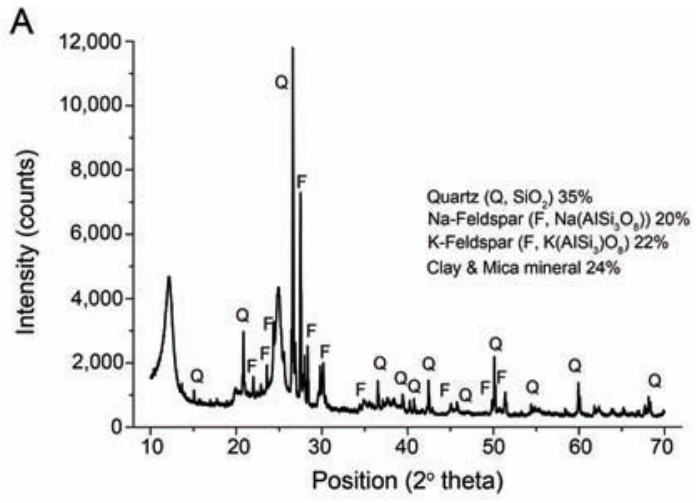

C

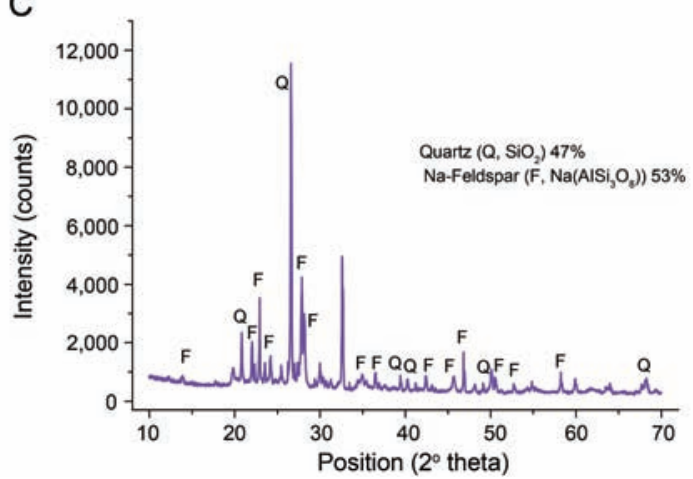

B

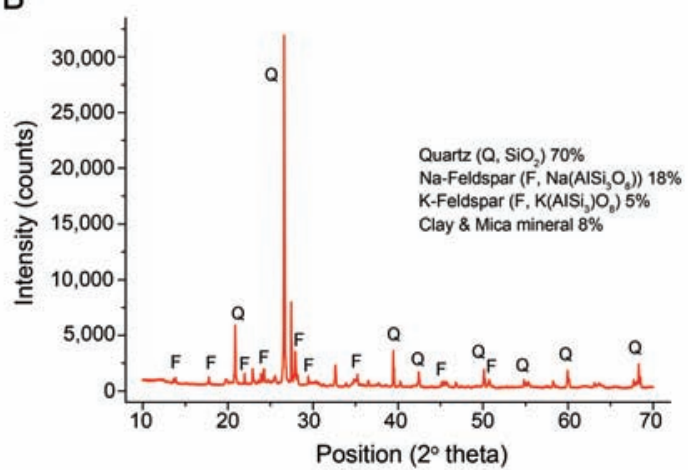

D

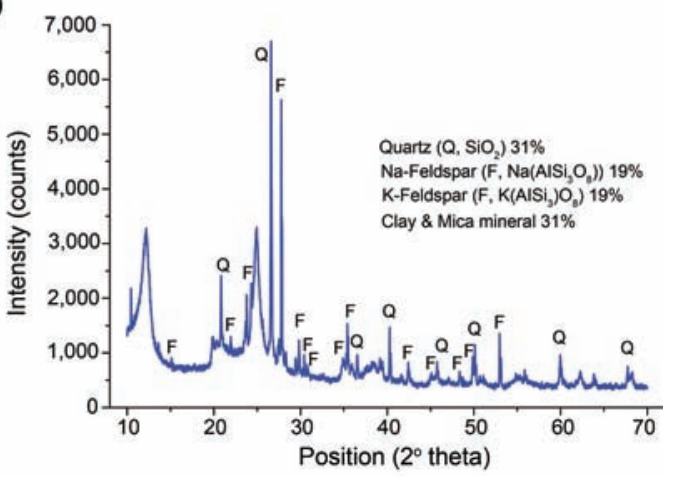

Fig. 3. XRD (X-ray diffraction) spectra of contaminating inorganic minerals separated from fresh ginsengs cultivated in different areas. (A) Punggi region, (B) Geumsan region, (C) Gangwon region, and (D) Gimpo region. 
sured for $\mathrm{TL}_{1}$ ) were used as a reference material after reirradiation (1 kGy) to confirm the reliability of the TL results [12]. The TL ratios (Table 2) for all non-irradiated samples were $<0.1$ and all irradiated samples $>0.1$, confirming the quality of the minerals on the TL discs to obtain valid identification results. The results of this study
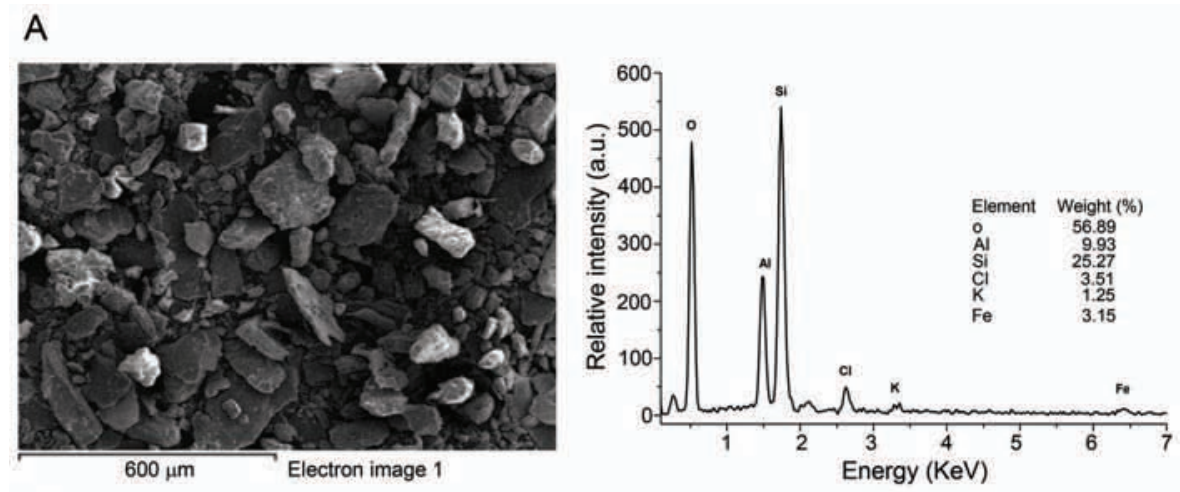

B
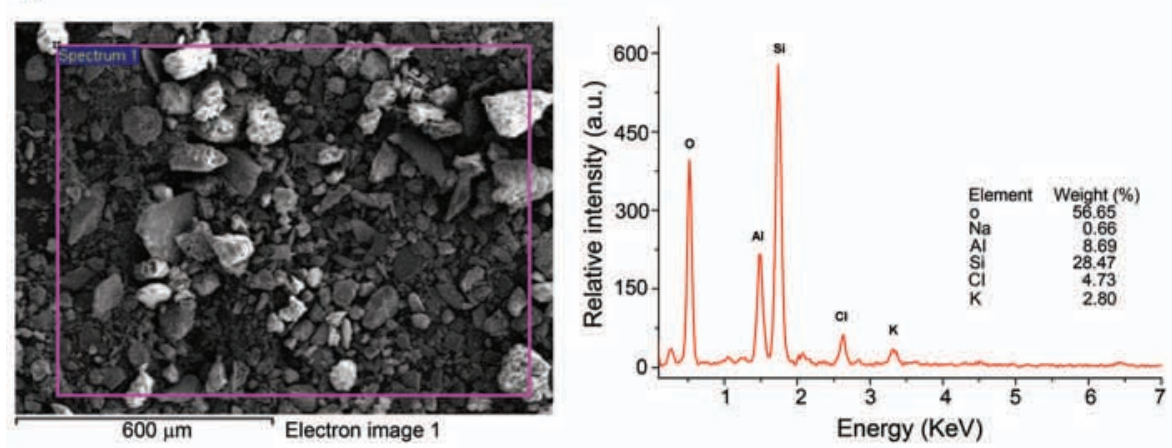

C
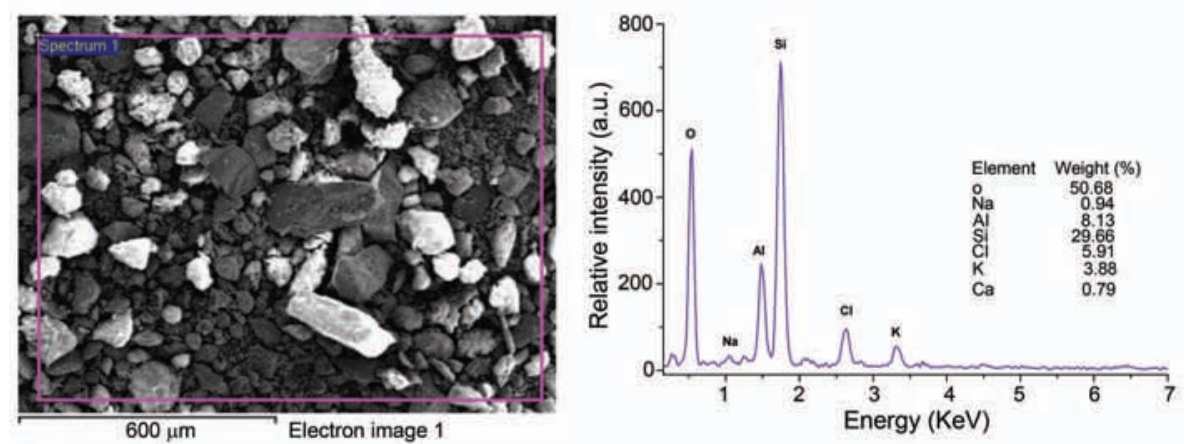

D
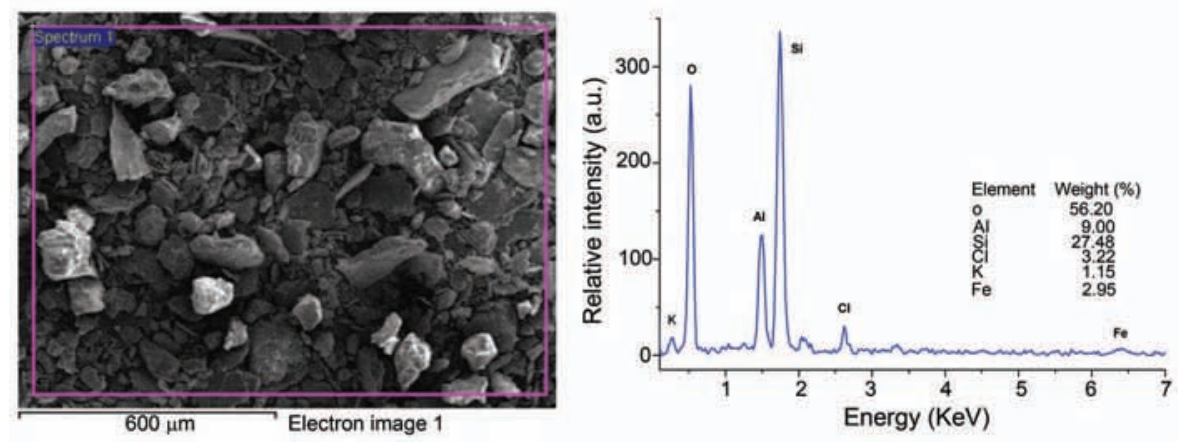

Fig. 4. SEM-EDX (scanning electron microscope-energy dispersive X-ray) spectra of contaminating inorganic minerals separated from fresh ginsengs cultivated in different areas. (A) Punggi region, (B) Geumsan region, (C) Gangwon region, and (D) Gimpo region. 
are in good agreement to those reported for irradiated fresh mushrooms [17], onions [13], kiwifruits [18], and sesame seeds [19].

\section{Mineral composition}

The radiation-induced luminescence properties are primarily dependent upon the quality and quantity of the inorganic minerals present on the surfaces of samples [12]. These minerals are present as contamination from the environment during cultivation, harvesting, transportation or processing. Hence, the mineral compositions of the separated inorganic dust greatly depend upon the regions where cultivation and processing are done [20,21]. The minerals separated from the fresh ginseng samples (cultivated in different regions) were analyzed by XRD spectroscopy shown in Fig. 3.

XRD spectroscopy requires a relatively large quantity of sample (about $0.5 \mathrm{~g}$ ), which is not always possible, especially in the case of foodstuffs with relatively small contaminating minerals. Therefore, SEM/EDX analysis was also done which requires a small amount (about 50 $\mathrm{mg}$ ) of separated minerals (Fig. 4). Both techniques gave comparable results showing that quartz and feldspar minerals were the main source of radiation-specific luminescence properties [21]. SEM/EDX analysis could be used as an alternative to XRD spectroscopy in the case of a small amount of mineral samples being present, which is required to be characterized by its composition. Among silicate minerals, feldspar minerals have very a high sensitivity to irradiation treatment and their TL properties usually define the overall TL glow curve characteristics of irradiated samples, where the effect of quartz and other minerals, even present in large quantities, is usually masked [21]. Feldspar minerals were present in all the samples and were in relative abundance in samples from the Gangwon and Punggi areas. The TL glow curves of the samples from these regions also showed more dosedependency with well-defined TL peaks (Fig. 1). Clay and mica minerals have poor radiation-induced luminescence properties. Relatively, the less dose-dependent TL results from the samples from the Gimpo region were justifiable considering the high concentrations of clay and mica minerals.

In conclusion, PSL could be effective in screening the samples with respect to their irradiation status. However, false positive results were observed due to the abundance of contaminating minerals on the surfaces of the fresh ginseng samples. A strong TL glow curve with maximum peak at about $200^{\circ} \mathrm{C}$ was a prominent characteristic of the irradiated samples regardless of their type and cultivation region. The confirmation of the TL results was possible by determining the TL ratio $\left(\mathrm{TL}_{1} / \mathrm{TL}_{2}\right)$. Feldspar and quartz minerals were responsible for the radiation-specific luminescence properties, where the TL glow curve shape and intensity were mainly defined by the feldspar contents of the contaminating inorganic minerals.

\section{ACKNOWLEDGEMENTS}

This work was supported by the National Research Foundation of Korea (NRF) grant funded by the Korean government (No. 2013R1A1A4A03006993).

\section{REFFERENCES}

1. Jin Y, Shin H, Song KB. Electron beam irradiation improves shelf lives of Korean ginseng (Panax ginseng C.A. Meyer) and red ginseng. J Food Sci 2007;72:C217-C222.

2. Minia R, Nemtanu MR, Brasoveanu M, Oproiu C. Accelerators use for irradiation of fresh medicinal herbs. In: Proceedings of European Particle Accelerator Conference; 2004 Jul 5-9; Lucerne, Switzerland. [place unknown]: European Physical Society Accelerator Group, 2004. p.2368-2370.

3. Kwon JH, Byun MW, Kim KS, Kang IJ. Comparative effects of gamma irradiation and phosphine fumigation on the quality of white ginseng. Radiat Phys Chem 2000;57:309-313.

4. Byun MW, Yook HS, Kang IJ, Chung CK, Kwon JH, Choi KJ. Comparative effects of gamma irradiation and ozone treatment on hygienic quality of Korean red ginseng powder. Radiat Phys Chem 1998;52:95-99.

5. Lee MK, Lee MH, Kwon JH. Sterilizing effect of electron beam on ginseng powders. Korean J Food Sci Technol 1998;30:1362-1366.

6. Yook HS, Kim SA, Byun MW, Kwon JH. Elimination of microorganisms contaminated in red ginseng powder by irradiation processing. Korean J Food Sci Technol 1996;28:366-370.

7. Kwon JH, Lee J, Waje C, Ahn JJ, Kim GR, Chung HW, Kim DH, Lee JW, Byun MW, Kim KS et al. The quality of irradiated red ginseng powder following transport from Korea to the United States. Radiat Phys Chem 2009;78:643-646.

8. Akram K, Ahn JJ, Kwon JH. Analytical methods for the identification of irradiated foods. In: Belotserkovsky E, Ostaltsov Z, eds. Ionizing radiation: applications, sources and biological effects. New York: Nova Science Publishers, 2012. p.1-48.

9. European Committee of Standardization. Foodstuffs: 
detection of irradiated food using photostimulated luminescence. EN 13751. Brussels: European Committee of Standardization, 2009.

10. Bayram G, Delincee H. Identification of irradiated Turkish foodstuffs combining various physical detection methods. Food Control 2004;15:81-91.

11. Ahn JJ, Akram K, Kwak JY, Jeong MS, Jang YD, Kwon $\mathrm{JH}$. Radiation-induced thermoluminescence characteristics of feldspar upon different heat and microwave treatments. J Lumin 2012;132:1964-1968.

12. European Committee of Standardization. Foodstuffs: thermoluminescence detection of irradiated food from which silicate minerals can be isolated. EN 1788. Brussels: European Committee of Standardization, 2001.

13. Ahn JJ, Kim GR, Akram K, Kim KS, Kwon JH. Luminescence characteristics of minerals separated from irradiated onions during storage under different light conditions. Radiat Phys Chem 2012;81:1215-1219.

14. Ahn JJ, Kim GR, Akram K, Kim KS, Kwon JH. Effect of storage conditions on photostimulated luminescence of irradiated garlic and potatoes. Food Res Int 2012;47:315320.

15. Kausar T, Kim BK, Yang JS, Byun MW, Kwon JH. Properties of pulsed photostimulated luminescence and thermoluminescence for detection of gamma-irradiated teas during storage. J Food Sci Nutr 2004;9:227-231.
16. Alberti A, Corda U, Fuochi P, Bortolin E, Calicchia A, Onori S. Light-induced fading of the PSL signal from irradiated herbs and spices. Radiat Phys Chem 2007;76:14551458.

17. Akram K, Ahn JJ, Kim GR, Kwon JH. Applicability of different analytical methods for the identification of gamma-irradiated fresh mushrooms during storage. Food Sci Biotechnol 2012;21:573-679.

18. Jo D, Kim BK, Kausar T, Kwon JH. Study of photostimulated- and thermo-luminescence characteristics for detecting irradiated kiwifruit. J Agric Food Chem 2008;56:1180-1183.

19. Lee J, Kausar T, Kim BK, Kwon JH. Detection of gamma-irradiated sesame seeds before and after roasting by analyzing photostimulated luminescence, thermoluminescence, and electron spin resonance. J Agric Food Chem 2008;56:7184-7188.

20. Ahn JJ, Kim GR, Akram K, Kim JS, Kwon JH. Changes in thermoluminescence properties of minerals separated from irradiated potatoes and garlic during long-term storage under different light conditions. Eur Food Res Technol 2012;235:75-82.

21. Soika C, Delincee H. Thermoluminescence analysis for detection of irradiated food-luminescence characteristics of minerals for different types of radiation and radiation doses. LWT Food Sci Technol 2000;33:431-439. 